\title{
Immersive audio properties for NCL media elements
}

\author{
Rafael Diniz \\ Computer Science Department \\ University of Brasília \\ Brasilia DF Brazil \\ rafael@riseup.net
}

\author{
Marcelo F. Moreno \\ Computer Science Department \\ Federal University of Juiz de Fora \\ Juiz de Fora MG Brazil \\ moreno@ice.uff.br
}

\begin{abstract}
With the introduction of immersive audio formats like MPEG-H and Dolby AC-4, TV terminals may allow end users to configure their experience by changing values of audio parameters directly or indirectly (audio profiles) via some kind of configuration user interface. In order to support more dynamic user interfaces for this kind of interactive audio setup, DTV apps should be able to manipulate such parameters as well. This contribution proposes the addition of immersive audio properties to media elements in NCL applications.
\end{abstract}

\section{KEYWORDS}

Immersive audio, interactivity, media properties, NCL

\section{Introduction}

ABNT NBR 15606-1 standard [1] specifies the data coding formats and protocols to be supported by middleware implementations for TV receivers under the Brazilian Terrestrial DTV system. Its most recent version (2018) includes new media formats, multimedia containers, streaming protocols and digital right management mechanisms, assembled into a new profile of TV receivers, called D-Profile TV receivers. Among these new media formats, immersive audio codecs MPEG-H and Dolby AC-4 are now included as optional support. Furthermore, these immersive audio codecs are also approved by the SBTVD Council to be supported as elementary streams in the broadcast, and new versions of the volumes of the ABNT NBR 15602 [2] containing support for these codecs should be published until the end of 2019 .

In traditional channel-based audio coding, various sound sources are mixed to create a final channel-based mix for a specific target loudspeaker layout. Each audio channel in the final product has to be reproduced by a loudspeaker at a well-defined position. This fixed audio mix is transmitted to the end-user with basically no means to adapt it to their needs, which may be a specific playback device or their personal preferences [3].

Different from channel-based codecs, immersive audio codecs support object-based coding and, therefore, the possibility to

In: Future of Interactive Television Workshop (V WTVDI), Rio de Janeiro, Brasil. Anais Estendidos do Simpósio Brasileiro de Sistemas Multimídia e Web (WebMedia). Porto Alegre: Sociedade Brasileira de Computação, 2019. (c) 2019 SBC - Sociedade Brasileira de Computação.

ISSN: $2596-1683$ personalize the immersive experience by handling object's parameters.

The term 'object-based media' has become commonly used to describe the representation of media content by a set of individual assets, together with metadata describing their relationships and associations. At the point of consumption these objects can be assembled to create an overall user experience. The precise combination of objects can be flexible and responsive to user, environmental and platform specific factors.

Essentially, the goal is to capture the creative intent of the producer and carry as much information as possible, required or desired, from the production side to the end-user, to ensure the best recreation possible on the consumer side. To achieve this, the final product of a production process will be an audio scene that is in turn composed of several objects. The metadata associated with each object includes, but is not limited to, the target position of the audio signal, its target loudness and a description of its actual content.[3]

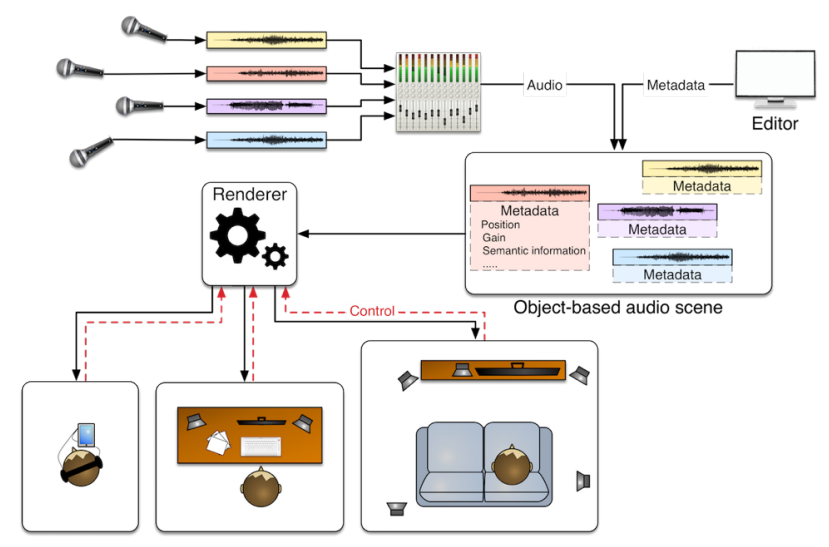

Figure 1. Conceptual overview of object-based audio production and consumption [2]

\section{Proposal}

In order to support immersive audio with interactivity support, DTV middleware specifications shall be modified in order to include an API that provides access to audio parameters. In the Brazilian Terrestrial DTV System and IPTV services compliant with ITU-T H.761, the Nested Context Language provides a harmonized API for handling media properties. The <media> 
element allows for the reference to media objects of any type and, for some media types, specific properties may apply, via the $<$ property $>$ element.

This contribution proposes the addition of immersive audio properties to media elements in NCL applications.

In immersive audio coding, each audio component (which can be a channel-based audio mix, an audio object or a HOA-based mix) has associated metadata properties like:

- the spatial change of its position, given in spherical coordinates (azimuth, elevation, radius)
- a linear gain that is to be applied by the object renderer with optional Loudness compensation

For instance, MPEG-H [4] defines the above metadata properties as well as interactivity control metadata, which specifies allowances and ranges for decoders to change some of those object metadata properties.

The following new properties should be added for immersive audio media objects:

\begin{tabular}{|c|c|c|c|c|}
\hline $\begin{array}{l}\text { Property name } \\
\text { (read-only) }\end{array}$ & Description & Type & Example & Observation \\
\hline soundPresetList & $\begin{array}{l}\text { List of preset labels defined in } \\
\text { the audio coding, separated by } \\
\text { comma }\end{array}$ & string & $\begin{array}{l}\text { "3DStadium, } \\
\text { Galvao, Adnet, } \\
\text { VisionImpairemen } \\
\text { t," }\end{array}$ & $\begin{array}{l}\text { Labels are chosen by } \\
\text { content producers and/or } \\
\text { broadcasters at encoding } \\
\text { time }\end{array}$ \\
\hline soundObjectList & $\begin{array}{l}\text { List of audio component labels } \\
\text { defined in the audio coding with } \\
\text { at least one interactivity setting } \\
\text { allowed, separated by comma }\end{array}$ & string & $\begin{array}{l}\text { "actor1, actor2, } \\
\text { carEngine, } \\
\text { weather, bgMusic, } \\
\text { streetNoise, } \\
\text { explosion" }\end{array}$ & $\begin{array}{l}\text { Labels are chosen by } \\
\text { content producers and/or } \\
\text { broadcasters at encoding } \\
\text { time }\end{array}$ \\
\hline $\begin{array}{l}\text { soundAzimuthOffsetRange } \\
\text { (label) }\end{array}$ & $\begin{array}{l}\text { Allowed minimum and } \\
\text { maximum offset for azimuth } \\
\text { control for label, in degrees } \\
\left(\text { minAzOffset }^{\circ}, \text { maxAzOffset }{ }^{\circ}\right) \text {. }\end{array}$ & $\begin{array}{l}\text { negative integer, } \\
\text { positive integer }\end{array}$ & $\begin{array}{l}-180,180 \\
0, \quad 0 \quad \text { (no control } \\
\text { allowed) }\end{array}$ & $\begin{array}{l}\text { This property replaces } \\
\text { "balanceLevel" in } \\
\text { immersive audio media. } \\
\text { label must be an audio } \\
\text { component label }\end{array}$ \\
\hline $\begin{array}{l}\text { soundElevationOffsetRange } \\
\text { (label) }\end{array}$ & $\begin{array}{l}\text { Allowed minimum and } \\
\text { maximum offset for elevation } \\
\text { control for label, in degrees } \\
\left(\text { minElOffset }^{\circ}, \text { maxElOffset }^{\circ}\right) \text {. }\end{array}$ & $\begin{array}{l}\text { negative integer, } \\
\text { positive integer }\end{array}$ & $\begin{array}{l}-90,90 \\
0, \quad 0 \quad \text { (no control } \\
\text { allowed) }\end{array}$ & $\begin{array}{l}\text { label must be an audio } \\
\text { components label }\end{array}$ \\
\hline $\begin{array}{l}\text { soundDistFactorRange } \\
\text { (label) }\end{array}$ & $\begin{array}{l}\text { Allowed minimum and } \\
\text { maximum distance change factor } \\
\text { for distance control of label } \\
\text { (minDistFactor, maxDistFactor) }\end{array}$ & $\begin{array}{l}\text { positive real, } \\
\text { positive real }\end{array}$ & $\begin{array}{l}0.00025,8.0 \\
0.0,0.0 \text { (no control } \\
\text { allowed) }\end{array}$ & $\begin{array}{l}\text { label must be an audio } \\
\text { component label }\end{array}$ \\
\hline soundGainRange(label) & $\begin{array}{l}\text { Allowed range for linear gain } \\
\text { control for label, in decibels } \\
\text { (minGain } \mathrm{db} \text {, maxGain } \mathrm{db} \text { ) }\end{array}$ & $\begin{array}{l}\text { negative integer, } \\
\text { positive integer }\end{array}$ & $\begin{array}{l}-63,31 \\
0, \quad 0 \quad \text { (no control } \\
\text { allowed) }\end{array}$ & $\begin{array}{l}\text { label must be an audio } \\
\text { component label }\end{array}$ \\
\hline
\end{tabular}

Table 1. Read-only properties (producer- or broadcaster-defined components, ranges and allowances):

\begin{tabular}{|l|l|l|l|l|}
\hline \multicolumn{1}{|c|}{$\begin{array}{c}\text { Property name } \\
\text { (read-only) }\end{array}$} & \multicolumn{1}{|c|}{ Description } & \multicolumn{1}{c|}{ Type } & \multicolumn{1}{c|}{ Example } & \multicolumn{1}{c|}{ Observation } \\
\hline soundAzimuthOffset(label) & $\begin{array}{l}\text { Current azimuth offset for } \\
\text { the integer } \\
\text { identified by label, in } \\
\text { degrees }\end{array}$ & $\begin{array}{l}\text { label must be an } \\
0 \text { (may denote non- } \\
\text { existent label) } \\
\text { audio component } \\
\text { label }\end{array}$ \\
\hline soundElevationOffset (label) & $\begin{array}{l}\text { Current elevation offset for } \\
\text { the integer } \\
\text { identified by label, in } \\
\text { degrees }\end{array}$ & $\begin{array}{l}\text { object/channel } \\
0 \text { (may denote non- } \\
\text { existent label) }\end{array}$ & $\begin{array}{l}\text { label must be an } \\
\text { audio component } \\
\text { label }\end{array}$ \\
\hline
\end{tabular}




\begin{tabular}{|l|l|l|l|l|}
\hline soundDistFactor(label) & $\begin{array}{l}\text { Current distance factor for } \\
\text { the positive real } \\
\text { identified by label }\end{array}$ & $\begin{array}{l}2.5 \\
0 \text { (may denote non- } \\
\text { existent label) }\end{array}$ & $\begin{array}{l}\text { label must be an } \\
\text { audio component } \\
\text { label }\end{array}$ \\
\hline soundGain(label) & $\begin{array}{l}\text { Current linear gain for the } \\
\text { object/channel identified } \\
\text { by label, in decibels }\end{array}$ & integer & $\begin{array}{l}15 \\
0 \text { (may denote non- } \\
\text { existent label) }\end{array}$ & $\begin{array}{l}\text { label must be an } \\
\text { audio component } \\
\text { label }\end{array}$ \\
\hline $\begin{array}{l}\text { soundLoudnessCompensation } \\
\text { (label) }\end{array}$ & $\begin{array}{l}\text { Enable or disable loudness } \\
\text { compensation after a a } \\
\text { change in gain setting }\end{array}$ & boolean & $\begin{array}{l}\text { true (enabled) } \\
\text { false (disabled) }\end{array}$ & $\begin{array}{l}\text { label must be an } \\
\text { audio component } \\
\text { label }\end{array}$ \\
\hline soundPreset(label) & $\begin{array}{l}\text { Current state of the preset } \\
\text { identified by label. }\end{array}$ & boolean & $\begin{array}{l}\text { true (on) } \\
\text { false (off or non- } \\
\text { existent label) }\end{array}$ & $\begin{array}{l}\text { label must be a } \\
\text { preset label. }\end{array}$ \\
\hline
\end{tabular}

Table 2. Read-write properties (immersive audio interactivity):

\section{Use case(s)}

The support in NCL of immersive audio features will allow seamless integrated between hybrid DTV apps and the audio interactivity features allowed by immersive audio codecs.

\section{REFERENCES}

[1] ABNT. ABNT NBR 15606-1: Data coding and transmission specification for digital broadcasting. Part 1: Data coding specification. 2018.

[2] ABNT. ABNT NBR 15602 series - Digital terrestrial television - Video coding, audio coding and multiplexing.

[3] WEITNAUER, Michael; MEIER, Michael. Object-based audio: The future of audio production, delivery and consumption. IRT website. 2018. Available at https://lab.irt.de/demos/object-based-audio/

[4] ISO/IEC. ISO/IEC 23008-3:2019: Information technology - High efficiency coding and media delivery in heterogeneous environments - Part 3: 3D audio. February 2019.

[5] MALHAM, Dave. High order Ambisonic systems. Abstracted from "Space in Music - Music in Space" Mphil thesis. University of York. April 2003. Available at https://www.york.ac.uk/inst/mustech/3d audio/higher order ambisonics.pdf

ABNT. ABNT NBR 15606-1: Data coding and transmission specification for digital broadcasting. Part 1: Data coding specification. 2018. 